\title{
Zoneamento climático para a grevílea (Grevillea robusta) para o Estado do Paraná
}

\author{
Elenice Fritzsons ${ }^{(1)}$, Antonio Aparecido Carpanezzi(1), Marcos Silveira Wrege ${ }^{(1)}$, Ananda Virgínia de Aguiar ${ }^{(1)}$
}

(1)Embrapa Florestas, Estrada da Ribeira, Km 111, CP 319, CEP 83411-000, Colombo, PR, elenice@cnpf.embrapa.br; carpa@cnpf.embrapa. br; wrege@cnpf.embrapa.br; ananda@cnpf.embrapa.br

\begin{abstract}
Resumo - A grevílea (Grevillea robusta A. Cunn) é uma espécie arbórea originária da Austrália e foi introduzida no Brasil no final do século 19. Novas progênies foram importadas e testadas pela Embrapa Florestas desde a década de 1990. Apesar do grande interesse em seu plantio no Paraná, até o momento, não há um zoneamento climático ou edafoclimático para a espécie. Foram definidos critérios restritivos e favoráveis ao cultivo da grevílea para o Estado do Paraná: temperatura média anual e temperatura média anual do mês de julho. As áreas mais indicadas para o plantio comercial situam-se no norte, noroeste, oeste e sudoeste, áreas mais quentes do estado. As áreas não recomendadas correspondem às do Planalto de Palmas e Guarapuava e do entorno, bem como de União da Vitória e bacias do Alto Iguaçu e Alto Capivari. As áreas toleradas estão entre as zonas não recomendadas e as zonas preferenciais, e situam-se ao longo de uma faixa central no estado.
\end{abstract}

Termos para indexação: Zoneamento, grevílea, zoneamento climático, Paraná.

\section{Climatic zoning for grevilea (Grevillea robusta) for the State of Parana, Brazil}

\begin{abstract}
Grevilea (Grevillea robusta A. Cunn) is a tree species from Australia and was introduced in Brazil in the late $19^{\text {Th }}$ century. New progenies were imported and tested by Embrapa Forestry since the 90s. Currently there is great interest in planting this species in Parana, but so far there is no edafoclimatic or climatic zoning for the species. The criteria that were defined restrictive and favorable to the plantation of grevílea: average annual temperature and annual average temperature of July. The areas most suitable for commercial plantation located in the north, northwest, west and south, warmer areas of the state. The areas recommended are not those of the Plateau de Palmas and Guarapuava and the environment, as well as Union of Victoria and the Upper Iguaçu basin and High Capivari basin. The areas between zones not recommended and preferred áreas are considered tolerated, and are situated along a strip center in the state
\end{abstract}

Index terms: Grevillea, zoning, climatic zoning, Parana State.

\section{Introdução}

A grevílea (Grevillea robusta A. Cunn) é uma espécie introduzida da Austrália e que se adapta facilmente a diferentes tipos de solos e climas. Apresenta rápido crescimento, especialmente por sua alta capacidade de extrair água e nutrientes por meio de seu sistema radicular profundo e ramificado (Martins et al., 2005; Harwood \& Getahun, 1990).

A espécie possui várias utilidades, como sombreamento de culturas agrícolas e pastagens, composição de cortinas de quebra-vento, produção de serrapilheira, mel, etc. A madeira de grevílea tem usos variados. O cerne é resistente e de boa qualidade para marcenaria, construção civil (Martins, 2003) e produção de lenha (Canto \&
Schneider, 2004), não sendo, porém, recomendada para uso externo, uma vez que apresenta baixa durabilidade (Martins, 2003). Apresenta peso específico de $0,564 \mathrm{~g}$ $\mathrm{cm}^{-3}$, massa específica de $510 \mathrm{~kg} \mathrm{~m}^{-3}$ e poder calorífico de $4.528 \mathrm{cal} \mathrm{g}^{-1}$ (Canto \& Schneider, 2004). No noroeste do Estado do Paraná, a grevílea é muito utilizada nas serrarias instaladas na região.

Apesar do interesse crescente pela grevílea por parte dos produtores no Estado do Paraná, até o momento, não há um zoneamento climático ou edafoclimático para orientá-los quanto aos locais mais propícios ao seu plantio. O zoneamento para espécies exóticas fundamenta-se, principalmente, nos resultados de ensaios bem sucedidos na região onde se pretende cultivar a espécie ou em regiões similares. No caso da falta destas 
informações, a indicação baseia-se, especialmente, em analogias ecológicas (homoclime analysis), de acordo com o princípio de que as espécies têm boas chances de sucesso nas regiões com condições ambientais parecidas com a sua área nativa ou nos lugares onde tenham sido introduzidas com êxito (Booth, 1996).

Entretanto, os resultados podem ser falsos, quando baseados apenas nas informações de seu nicho climático, sem referenciar, amibientalmente, os locais onde as espécies foram bem sucedidas. Como, por exemplo, espécies localizadas ao longo do eixo de drenagem podem se beneficiar do fluxo de água subterrânea e mascarar ou atenuar os efeitos do macroclima. Outra questão se refere à presença ecótipos que devem ser identificados.

De acordo com Golfari (1978), quando há experimentação local com povoamento de certa idade, o comportamento de uma espécie exótica pode ser avaliado pelo diagnóstico visual nas plantações existentes, levando-se em consideração diversos fatores: crescimento anual, porcentagem de sobrevivência, uniformidade de crescimento, sistema de ramificação, tendência para a derrama, forma normal e aberrante do fuste e da copa, idade de início da floração e frutificação, longevidade, resistência a fatores físicos adversos e parasitas e, ainda, resistência a agentes físicos desfavoráveis, como a incidência de geadas. Essas observações de campo fornecerão informações sobre as possibilidades de sucesso na introdução da espécie naquele ambiente.

Nos locais de distribuição natural na Austrália, a grevílea é uma espécie colonizadora de áreas desmatadas e apresenta rápido crescimento nos primeiros anos, quando, depois de certa fase, seu crescimento diminui. A espécie apresenta desvantagem na competição com outras espécies: em locais muito úmidos; quando há ocorrência de fogo, mesmo de baixa intensidade; em locais onde ocorrem baixas temperaturas de inverno; e em solos muitos secos (Harwood, 1992).

O crescimento e o desenvolvimento da grevílea são mais intensos na estação quente, com chuvas constantes, sendo o crescimento vigoroso nos seis primeiros anos, onde o clima e solos são adequados (Harwood, 1992). Martins e Neves (2005) afirmam que a grevílea, quando introduzida em condições de solos e clima adequados (temperatura média anual entre $15^{\circ} \mathrm{Ce} 18^{\circ} \mathrm{C}$, precipitação entre $1.000 \mathrm{~mm}$ a $2.000 \mathrm{~mm}$ ), pode atingir incremento anuais de $2 \mathrm{~m}$ em altura e $2 \mathrm{~cm}$ em diâmetro, como média nos primeiros 5 a 10 anos de idade.
Harwood (1992) afirma que a grevílea é suscetível a geadas severas resultando, inicialmente, em morte dos brotos terminais mais tenros e poucas chances de sobrevivência quando a temperatura mínima chega a $-10{ }^{\circ} \mathrm{C}$ (Harwood \& Booth, 1992). Martins (2000), em experimento realizado em Ponta Grossa, PR, observou morte das gemas terminais, redução de crescimento e comprometimento da forma das árvores como consequência de geada. O problema se agrava nos locais onde as geadas podem ocorrer de forma sequencial, ou seja, vários eventos de geadas em curto período de tempo, o que pode ocasionar a morte de plantas jovens. Em plantios de grevílea no Paraná, o problema referente às geadas para a grevílea ocorre em plantas jovens, especialmente provenientes de plantios tardios, ou então de plantios em solos de baixa fertilidade, os quais não favoreceram seu desenvolvimento nas estações anteriores ao inverno.

Com base no resultado dos plantios efetuados nos estados do Paraná e São Paulo, este trabalho tem como objetivo definir os critérios climáticos restritivos e favoráveis ao cultivo da grevílea, e aplicá-los para produzir a carta de zoneamento climático pelo método da sobreposição de cartas e relevo.

\section{Material e métodos}

A introdução da grevílea não é recente, pois ocorreu no final do século 19, quando vieram as primeiras sementes no Brasil, provenientes de poucas matrizes. Em 1992, a Embrapa Florestas importou 20 procedências da espécie da Austrália e, no ano seguinte, 126 progênies de 23 procedências, visando à formação de uma base genética ampla. Entre 1993 a 1994, foram instalados testes de progênies e procedências com este material em algumas regiões dos estados do Paraná, São Paulo e Mato Grosso do Sul (Tabela 1). Após a implantação dessas áreas, os plantios foram manejados e transformados em áreas de produção de sementes (APS) e pomares de produção de sementes por mudas (PSM).

Os critérios restritivos ao cultivo da grevílea foram definidos com base nas informações obtidas em publicações técnico-científicas das áreas experimentais de grevílea no Estado do Paraná e São Paulo (Shimizu et al. 1998, Lins et al, 2001, Martins et al., 2002; Martins \& Neves, 2004, Martins \& Shimizu, 2003; Martins et al., 2005; Martins \& Neves, 2005). O foco dessas informações foi direcionado aos experimentos 
com a grevílea, relacionando-os aos seguintes fatores: crescimento, possíveis problemas fitossanitários, aparência geral do plantio e outros que possam dar indicação da adaptabilidade da grevílea, sempre levando em consideração a relação com aspectos climáticos. Também foram escolhidos os critérios climáticos para definir áreas preferenciais e não recomendadas ao plantio. As áreas em que o plantio é tolerado foi considerada zona intermediária entre as duas anteriores.

Os dados climáticos ausentes na literatura consultada foram obtidos no banco de dados das estações mais próximas das áreas experimentais (Fritzsons et al., 2008), tendo sempre o cuidado de verificar a exata localização em coordenadas geográficas, relevo e altitude.

As informações sobre os experimentos no Estado de São Paulo foram utilizadas como base para reforçar os resultados obtidos com a grevílea no Estado do Paraná, uma vez que o norte do estado apresenta uma grande similaridade climática com o Estado de São Paulo.
De posse da definição dos critérios climáticos a serem utilizados no zoneamento, foram compostas as equações de regressão para representar isolinhas de temperatura, utilizando dados climáticos do Iapar/Simepar, dados de altitude e coordenadas geográficas.

\section{Resultados e discussão}

Na maioria dos locais onde foram implantados os testes de progênies e procedências de grevílea pela Embrapa Florestas, a espécie apresentou uma boa desempenho em diâmetro, altura e sobrevivência (Martins \& Neves, 2005). Atualmente, os testes encontram-se desbastados e foram transformados em áreas de produção de sementes e pomares de sementes por mudas e tem entre seis e nove anos de idade (Tabela 1). De acordo com Martins et. al. (2009), entre as procedências testadas, as de Mann River, Fine Flower e Rapville, todas originárias do Estado de New South Wales produziram maiores volumes cilíndricos.

Tabela 1. Situação e localização das áreas experimentais de grevílea.

\begin{tabular}{lll}
\hline Experimento & Localização & Situação em 2007 \\
\hline Teste de progênies & Ponta Grossa, PR & Bom desempenho \\
APS - População base & Ponta Grossa, PR & Bom desempenho \\
PSM - Primeira geração & Cândido de Abreu, PR & Desempenho regular. Precisa de desbaste \\
PSM - Primeira geração & Pres. Castelo Branco, PR & Ótimo desempenho \\
PSM - Primeira geração & Nova Esperança, PR & Ótimo desempenho. Foi cortada (corte raso). \\
PSM - Primeira geração & Anhembi, SP & Ótimo desempenho \\
PSM - Primeira geração & Foz do Iguaçu, PR & Bom desempenho. Presença expressiva de plantas no sub-bosque \\
PSM - Primeira geração & Quedas do Iguaçu, PR & Desempenho regular \\
PSM - Segunda geração & Avaré, PR & Bom desempenho \\
PSM - Segunda geração & Londrina, PR & Ótimo desempenho \\
\hline APS - Área de produção de sementes, PSM - Pomar de sementes por muda &
\end{tabular}

As amplitudes climáticas dos locais de plantio da grevílea encontram-se entre os seguintes limites (Tabela 2): Temperatura média de $17,9{ }^{\circ} \mathrm{C}$ (Ponta Grossa) a $24,8{ }^{\circ} \mathrm{C}$ (Ilha Solteira); Temperatura média anual de julho de $13,9{ }^{\circ} \mathrm{C}$ (Ponta Grossa) a $21{ }^{\circ} \mathrm{C}$ (Ilha Solteira); Temperatura média anual de janeiro de $21,4{ }^{\circ} \mathrm{C}$ (Ponta Grossa) a $27^{\circ} \mathrm{C}$ (Paranavaí); Precipitação média anual de
$1.309 \mathrm{~mm}$ (Ilha Solteira) a $1.964 \mathrm{~mm}$ (Foz do Iguaçu); Evaporação média anual de $791 \mathrm{~mm}$ (Cândido de Abreu) a $1.422 \mathrm{~mm}$ (Londrina); Total médio da precipitação do trimestre de verão de $615 \mathrm{~mm}$ (Ilha Solteira) a 512 mm (Foz do Iguaçu); Total médio da precipitação do trimestre de inverno de 75,3 $\mathrm{mm}$ (Anhembi) a $304 \mathrm{~mm}$ (Cândido de Abreu). 
Tabela 2. Características climáticas dos locais de experimentação da grevílea.

\begin{tabular}{|c|c|c|c|c|c|c|c|c|c|}
\hline \multirow[b]{2}{*}{$\begin{array}{l}\text { Caracteristicas } \\
\text { climáticas }\end{array}$} & \multicolumn{9}{|c|}{ Localidades } \\
\hline & $\begin{array}{c}\text { (Nova } \\
\text { Esperança } \\
\text { e Presidente } \\
\text { Castelo } \\
\text { Branco), PR }\end{array}$ & $\begin{array}{c}\text { Ponta } \\
\text { Grossa }^{(1)} \\
\text { (estação B), } \\
\text { PR }\end{array}$ & $\begin{array}{c}\text { Quedas } \\
\text { do Iguaçu } \\
\text { / Salto }^{(1)} \text {, } \\
\text { PR }\end{array}$ & $\begin{array}{c}\text { Anhembi, } \\
\text { SP }\end{array}$ & $\begin{array}{c}\text { Avaré( }^{(4)} \\
\text { SP }\end{array}$ & $\begin{array}{c}\text { Foz do } \\
\text { Iguaçu, PR }\end{array}$ & $\begin{array}{c}\text { Ilha } \\
\text { Solteira }^{(4)} \text {, } \\
\text { PR }\end{array}$ & $\begin{array}{c}\text { Cândido } \\
\text { de Abreu } \\
\text { PR }\end{array}$ & $\begin{array}{c}\text { Londrina }^{(1)}, \\
\text { PR }\end{array}$ \\
\hline $\begin{array}{l}\text { Temp. média máx. } \\
\text { anual }\left({ }^{\circ} \mathrm{C}\right)\end{array}$ & 28,4 & 24,1 & 27 & $28,7^{(2)}$ & 26,5 & 28 & 31,3 & 26,5 & 23,7 \\
\hline $\begin{array}{l}\text { Temp. média min. } \\
\text { anual }\left({ }^{\circ} \mathrm{C}\right)\end{array}$ & 17,7 & 13,4 & 15,5 & $15,8^{(2)}$ & 14,7 & 17,6 & 18,4 & 15,1 & 16,0 \\
\hline $\begin{array}{l}\text { Temp. Máx. abs. } \\
\text { período }\left({ }^{\circ} \mathrm{C}\right)\end{array}$ & 41,5 & 36,2 & 38,6 & sem dados & sem dados & 39,5 & sem dados & 37,3 & 39,2 \\
\hline $\begin{array}{l}\text { Temp. Min. abs. } \\
\text { Período }\left({ }^{\circ} \mathrm{C}\right)\end{array}$ & $-3,0$ & $-6,0$ & $-5,5$ & sem dados & sem dados & $-0,6$ & sem dados & $-2,5$ & $-1,3$ \\
\hline $\begin{array}{l}\text { Temp. média anual } \\
\left({ }^{\circ} \mathrm{C}\right)\end{array}$ & 22,1 & 17,9 & 20,1 & $21,0^{(2)}$ & 20,6 & 22,3 & 24,8 & 19,8 & 21,0 \\
\hline $\begin{array}{l}\text { Amplitude térmica } \\
\text { anual }\left({ }^{\circ} \mathrm{C}\right)\end{array}$ & 6,9 & 7,6 & 8,9 & $6,6^{(2)}$ & 7,6 & 9,1 & 4,2 & 8,2 & 7,0 \\
\hline $\begin{array}{l}\text { Temp. média julho } \\
\left({ }^{\circ} \mathrm{C}\right)\end{array}$ & 18,2 & 13,9 & 15,4 & $17,1^{(2)}$ & 16,5 & 17,5 & 21 & 15,1 & 16,9 \\
\hline $\begin{array}{l}\text { Temp. média janei- } \\
\text { ro }\left({ }^{\circ} \mathrm{C}\right)\end{array}$ & 25,1 & 21,4 & 24,3 & $23,7^{(2)}$ & 23,1 & 26,6 & 27,0 & 23,3 & 23,9 \\
\hline $\begin{array}{l}\text { Precip. média total } \\
\text { anual }(\mathrm{mm})\end{array}$ & 1.485 & 1.521 & 1.964 & $1350,0^{(2)}$ & 1.388 & $1.691,2$ & 1.309 & 1.672 & 1584 \\
\hline $\begin{array}{l}\text { Total médio anual } \\
\text { trim. Verão }(\mathrm{mm})\end{array}$ & 513,3 & 485,4 & 533,9 & $552,7^{(2)}$ & 591,5 & 512,2 & 615,1 & 524 & 601 \\
\hline $\begin{array}{l}\text { Total médio anual } \\
\text { trim. inverno }(\mathrm{mm})\end{array}$ & 208,2 & 280,2 & 374,6 & $109,9^{(2)}$ & 151,9 & 270,4 & 75,3 & 304 & 205 \\
\hline $\begin{array}{l}\text { Diferença entre } \\
\text { trimestres }(\mathrm{mm})\end{array}$ & 305 & 205 & 159,00 & $434,8^{(2)}$ & 439,6 & 232 & 539,8 & 228 & 396 \\
\hline $\begin{array}{l}\text { Evap. média total } \\
\text { anual }(\mathrm{mm})\end{array}$ & 1.320 & 930,3 & $1.038,2$ & $\begin{array}{l}1.055^{(3)} \\
\text { (ETR) }\end{array}$ & 945 & $\begin{array}{c}908,7 \\
\text { (estação A) }\end{array}$ & sem dados & 791 & 1422 \\
\hline $\begin{array}{l}\text { Umidade relativa } \\
(\%)\end{array}$ & 69 & 77,5 & 75,8 & sem dados & sem dados & 80,2 & sem dados & 77 & 70,4 \\
\hline $\begin{array}{l}\text { Insolação total } \\
\text { (horas) }\end{array}$ & 2.640 & $2.115,3$ & $2.379,3$ & sem dados & sem dados & & sem dados & 2.461 & 2.607 \\
\hline $\begin{array}{l}\text { Período } \\
\text { monitorado (anos) }\end{array}$ & 34 & 55 & 36 & $29^{(2)}$ & 29 & 11 & sem dados & 18 & 32 \\
\hline Clima (Köppen) & $\mathrm{Cfa}$ & $\mathrm{Cfb}$ & $\mathrm{Cfa}$ & Aw & Cwa & $\mathrm{Cfa}$ & Aw & $\mathrm{Cfb}$ & $\mathrm{Cfa}$ \\
\hline $\begin{array}{l}\mathrm{N}^{\mathrm{o}} \text { de meses com } \\
\text { pptação }<60 \mathrm{~mm}\end{array}$ & 1 & 0 & 0 & $3 * *$ & 2 & 0 & 4 & 0 & 1 \\
\hline
\end{tabular}

(1) Iapar (2009), (2) EE Anhembi (Esalq), CPA/Unicamp, ${ }^{\left({ }^{(2)}\right.}$ DAEE, ${ }^{(4)}$ Embrapa NMA; Esalq e Cepagri

$\mathrm{Cfb}$ - Clima Subtropical Úmido (Mesotérmico), com média do mês mais quente inferior a $22^{\circ} \mathrm{C}$ e do mês mais frio inferior a $18{ }^{\circ} \mathrm{C}$, sem estação seca, verão brando e geadas severas, demasiadamente frequentes. Distribui-se pelas terras mais altas dos planaltos e das áreas serranas (Planaltos de Curitiba, Campos Gerais, Guarapuava, Palmas, etc.); Cfa - Clima subtropical úmido (Mesotérmico), com média do mês mais quente superior a $22^{\circ} \mathrm{C}$ e no mês mais frio inferior a $18{ }^{\circ} \mathrm{C}$, sem estação seca definida, verão quente e geadas menos frequentes. Distribuindo-se pelo norte, centro, oeste e sudoeste do estado, pelo Vale do Rio Ribeira e pela vertente litorânea da Serra do Mar; Aw - Tropical chuvoso com inverno seco, e mês mais frio com temperatura média superior a $18{ }^{\circ} \mathrm{C}$. O mês mais seco tem precipitação inferior a $60 \mathrm{~mm}$ e apresenta chuvas menos abundantes do que as dos climas Af e Am, desigualmente distribuídas ao longo do ano. A precipitação média anual fica compreendida entre $1.000 \mathrm{~mm}$ e $1500 \mathrm{~mm}$; Cwa - Clima temperado úmido, com Inverno seco e verão quente, que abrange toda a parte central do estado e é caracterizado pelo clima tropical de altitude, com chuvas no verão e seca no inverno, com a temperatura média do mês mais quente superior a $22^{\circ} \mathrm{C}$. Algumas áreas serranas, com o verão ameno, são classificadas no tipo Cwb, onde a temperatura média do mês mais quente é inferior a $22^{\circ} \mathrm{C}$ e durante pelo menos quatro meses é superior a $10^{\circ} \mathrm{C}$; ETR- Evapotranspiração real. 
$\mathrm{Na}$ Tabela 2 foi incluído Selvíria, cuja estação climatológica está localizada em Ilha Solteira. Nesta localidade, a plantação não apresentou bom resultado, pois, de acordo com Moraes (2007), após quatro anos de idade, nesse experimento, houve falhas (morte de plantas) decorrentes de fatores não conhecidos. Na época detectaram a ocorrência de nematóides no solo onde se encontrava o teste de progênies. Portanto, este pode ser um fator que contribuiu para a morte das plantas. Entretanto, de acordo com Martins (2007), Selvíria também apresenta um déficit hídrico que pode limitar o crescimento da grevílea, pois, em média, há quatro meses do ano com precipitações menores que $60 \mathrm{~mm}$ (Tabela 2).

A precipitação no Estado do Paraná não constitui fator limitante à grevílea, pois a precipitação média anual que ocorre em Anhembi (1.350 mm) é menor do que qualquer outra precipitação média anual em todo o Paraná, com exceção dos dados das estações de Maringá (1.307 mm), Jacarezinho (1.344 mm), Cerro Azul (1.330 $\mathrm{mm})$, Rio Negro (1.329 mm) e Salto Caxias (1.334 mm) (Fritzsons et. al, 2008).

Quanto à temperatura, considerando apenas os locais de plantio no Paraná, a temperatura média das máximas anuais varia de $23,7^{\circ} \mathrm{C}$ (Londrina) a $28,4^{\circ} \mathrm{C}$ (Paranavaí) e a temperatura média das mínimas anuais de $13,4^{\circ} \mathrm{C}$ (Ponta Grossa) a $17,7^{\circ} \mathrm{C}$ (Paranavaí). Dos locais de experimentação presentes na Tabela 1 , em termos de temperatura máxima, Paranavaí é um dos locais mais quentes do estado, sendo, inclusive, mais quente em julho e em janeiro que Anhembi (São Paulo), e perdendo apenas para Selvíria, no Mato Grosso do Sul (estação meteorológica de Ilha Solteira em São Paulo). Como o plantio da grevílea em Nova Esperança (próximo a Paranavaí) foi considerado de ótimo desempenho, podese concluir que não há limitação para a grevílea quanto à temperatura máxima no Estado do Paraná.

Os dados de ocorrência de geadas observadas para Paranavaí apontam 1,9 geadas ao ano, para Quedas do Iguaçu, 3,2 (Kim et al., 2003), para Ponta Grossa, 10,9 ao ano, e para Anhembi, duas a três geadas a cada dez anos (Unicamp, 2007). Assim, dentre os locais de experimentação, Ponta Grossa corresponde ao maior número médio de geadas por ano. Neste município, há parcelas que apresentam bom desempenho, especialmente as localizadas fora das zonas de baixada, possivelmente, porque nelas as geadas são mais frequentes e intensas, além da tendência dos solos em restrição na drenagem.

Como os dados de geadas observadas não são monitorados para todas as estações meteorológicas no Paraná, em trabalhos de zoneamento de culturas perenes, adota-se a temperatura média do mês mais frio (julho) como melhor descritor do rigor invernal, a exemplo de Caramori \& Maneti Filho (1993).

Com base nessas informações, foi elaborada a Tabela 3, que apresenta os critérios (condições climáticas preferenciais, toleradas e não recomendadas) para o plantio da grevílea para o Estado do Paraná.

Tabela 3. Critérios estabelecidos para o plantio da grevílea no Estado do Paraná.

\begin{tabular}{lcclc}
\hline Condições climáticas & $\begin{array}{c}\text { Temp. média } \\
\text { julho }\left({ }^{\circ} \mathbf{C}\right)\end{array}$ & $\begin{array}{c}\text { Temp. média } \\
\text { anual }\left({ }^{\circ} \mathbf{C}\right)\end{array}$ & Recomendação & Finalidade de plantio \\
\hline Preferencial & $\geq 15$ & $\geq 19$ & $\begin{array}{l}\text { Preferência para solos } \\
\text { profundos e bem drenados }\end{array}$ & $\begin{array}{l}\text { Comercial } \\
\text { Tolerada (com restrições) }\end{array}$ \\
Entre 13,6 e 14,9 & Entre 17,6 e 18,9 & $\begin{array}{l}\text { Não utilizar em áreas de baixa } \\
\text { vertente e fundos de vale }\end{array}$ & $\begin{array}{l}\text { Experimentação, } \\
\text { comprovação ou comercial } \\
\text { em pequena escala }\end{array}$ \\
Não recomendada & $\leq 13,5$ & $\leq 17,5$ & & \\
\hline
\end{tabular}

Como as baixas temperaturas podem constituir um fator restritivo às plantações da grevílea, as zonas preferenciais, voltadas aos plantios comerciais, devem apresentar a temperatura média do mês de julho maior ou igual à temperatura de Ponta Grossa $\left(14^{\circ} \mathrm{C}\right)$. $\mathrm{O}$ frio causa uma diminuição no crescimento outonal, pois o crescimento e o desenvolvimento da grevílea são mais intensos na estação quente, com chuvas constantes.
Este aspecto é importante, especialmente, considerando os plantios comerciais (Harwood, 1992). Na Tabela 3 foi admitido um limite de segurança para a faixa preferencial, em relação à temperatura média de julho de Ponta Grossa $\left(1{ }^{\circ} \mathrm{C}\right)$, levando em consideração a recomendação para plantio comercial.

As zonas não recomendadas (ou recomendadas com restrições) são aquelas onde a temperatura média do mês 
de julho é menor que $13{ }^{\circ} \mathrm{C}$, e a temperatura média anual menor que $17,3{ }^{\circ} \mathrm{C}$, a exemplo das áreas do Planalto de Guarapuava, Palmas e Clevelândia, onde Palmas apresenta um número médio de 23 geadas por ano (Iapar, 2007). Ainda dentro desta faixa, estão algumas outras localidades também nas zonas mais frias do estado (Castro, Pinhais, Lapa e Fernandes Pinheiro).

Nas zonas toleradas estão as outras áreas, intermediárias entre as não recomendadas e as preferenciais. Nessas áreas deve-se evitar plantar em fundos de vale e baixa vertente, sendo os plantios voltados principalmente para experimentação ou comprovação. Mesmo nestas zonas, os locais de elevada altitude também deverão ser evitados, devido ao frio.

No Paraná, as áreas preferenciais estão mais relacionadas ao clima Cfa da classificação de Köeppen (norte, centro, oeste e sudoeste do estado, Vale do Rio Ribeira e vertente litorânea da Serra do Mar), enquanto que as áreas consideradas não recomendadas estão mais relacionadas ao clima $\mathrm{Cfb}$ (Planaltos de Curitiba, Campos Gerais, Guarapuava, Palmas, etc.).

Na carta de zoneamento climático da grevílea (Figura 1) foram definidas três zonas (preferencial, tolerada e não recomendada), observando-se que a preferencial situase nas áreas mais quentes do estado, (norte, noroeste e sudoeste) e ainda no Vale do Ribeira (Cerro Azul) e no litoral. Entretanto, as áreas do litoral constituem áreas restritivas ao cultivo, por serem áreas, em sua maioria, protegidas por Lei.

A zona não recomendada é a porção sul do estado, onde há grande probabilidade de ocorrência de geadas no inverno e a temperatura média anual mais baixa acaba restringindo um bom crescimento da grevílea. A zona tolerada situa-se entre a preferencial e a não recomendada e se presta de forma favorável à experimentação, pois há diversas situações climáticas e microclimáticas que precisam ser melhor avaliadas.

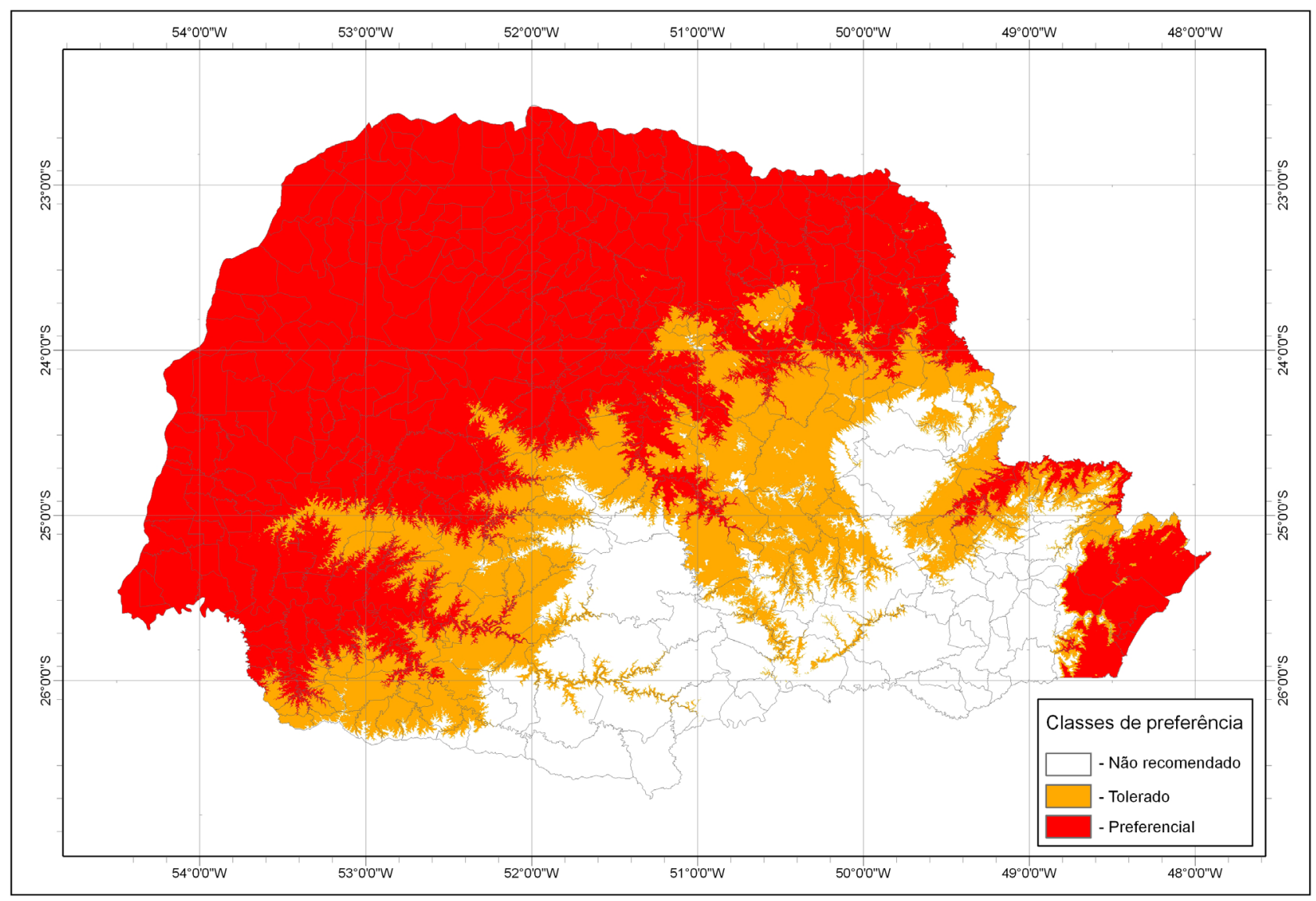

Figura 1. Carta de zoneamento climático da grevílea. 


\section{Considerações finais}

As temperaturas média anual e média anual de julho foram os critérios utilizados para estabelecer o zoneamento climático da grevílea com as classes preferencial, tolerada e não recomendada, considerando as informações de publicações técnico-científicas e dos locais onde a grevílea apresentou bom desempenho.

A precipitação não constitui um problema no Estado do Paraná para o plantio de grevílea, mas pode limitar o crescimento em estágios iniciais de implantação de um povoamento, especialmente se a época de plantio for desfavorável.

As áreas mais indicadas para o plantio comercial situam-se no norte, noroeste, oeste e sudoeste, áreas mais quentes do estado. Nas áreas consideradas não recomendadas, ocorre frio excessivo e temperaturas muito baixas no mês de julho, com ocorrência de geadas fortes e/ou frequentes. As áreas não recomendadas correspondem as do Planalto de Palmas e Guarapuava e do entorno, bem como de União da Vitória e bacias do Alto Iguaçu e Alto Capivari.

As áreas toleradas, entre as zonas não recomendadas e as zonas preferenciais, situam-se ao longo de uma faixa central no estado. São áreas intermediárias, onde é possível estabelecer plantações de grevílea, destinadas apenas à experimentação, comprovação ou plantio comercial, mas em pequena escala e em locais fora das zonas de baixada, pois nessas áreas ocorrem geadas com maior frequência.

Este zoneamento climático da grevílea é de caráter preliminar, visto que novas áreas de observação serão instaladas em locais distintos e, com o monitoramento mais frequente destas áreas e dos plantios comerciais, novas informações poderão ser agregadas como subsídio a um aprimoramento deste zoneamento.

\section{Agradecimentos}

Ao Iapar, pelos dados cedidos de geadas observadas; aos Drs. Emerson Martins e Vanderley Porfírio-da-Silva, pelas informações prestadas.

\section{Referências}

BOOTH, T. H. (Ed.). Matching trees and sites: proceedings of an international workshop held in Bangkok, Thailand, 27-30 mar. 1996. Canberra: ACIAR, 1996.128p.
Canto, Juliana Lorenzi; Schneider, Paulo Renato. Crescimento da Grevillea robusta A. Cunn. na depressão central do Rio Grande do Sul, Brasil. Ciência Florestal, Santa Maria, v. 14, n. 2, p. 29-35. 2004.

CARAMORI, P. H.; MANETTI FILHO, J. Proteção dos cafeeiros contra geadas. Londrina, 1993. 28 p. (IAPAR: Circular Técnica, 79).

CEPAGRI, UNICAMP. Clima dos Municípios Paulistas. Disponível em http://www.cpa.unicamp.br/outras-informacoes/ clima_muni_052.html. Data da disponibilidade 24/06/2009

EMBRAPA MONITORAMENTO POR SATÉLITE; ESALQUSP. Disponível em http:/www.bdclima.cnpm.embrapa.br/ resultados/balanco.php? $\mathrm{UF}=\& \mathrm{COD}=257$. Data da disponibilidade: 03/06/2009.

FRITZSONS, E.; CARPANEZZI, A. A.; MANTOVANI, L. E. Elaboração de um banco de dados climáticos para o Estado do Paraná. Colombo, 2008. 168p. (Embrapa Florestas: Documentos, 168).

GOLFARI, L.; CASER, R. L.; MOURA, V. P. G. Zoneamento ecológico esquemático para o reflorestamento no Brasil: $2^{\mathrm{a}}$ aproximação. Belo Horizonte: Embrapa Centro de Pesquisa do Cerrado, 1978. 66p. (PRODEPEF, Série Técnica 11).

HARWOOD, C. E. (Ed.). Grevillea robusta in agroforestry and forestry: proceedings of an international workshop. Nairobi: ICRAF, 1992. 190p.

HARWOOD, C. E.; GETAHUN, A. Australian tree finds success in Africa. Agroforestry Today, n. 2, p. 10, 1990.

HARWOOD, C. E.; BOOTH, T. H. Status of Grevillea robusta in forestry and agroforestry. In: HARWOOD, C. E. (ed.). HARWOOD, C. E. (Ed.). Grevillea robusta in agroforestry and forestry: proceedings of an international workshop. Nairobi: ICRAF, 1992. pp.9-16.

. Médias históricas. Disponível em: http://www.iapar.

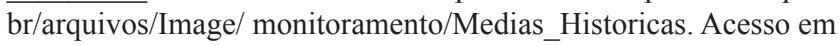
26 mai 2009.

KIM, I. ; GRODZKI, L.; CARAMORI, P H ; VISSOTO, S. Análise da ocorrência de geadas no Estado do Paraná. Revista Brasileira de Agrometeorologia, Santa Maria, 11(1): 99-106, 2003.

MARTINS E. G.; SHIMIZU, J. Y.; FERREIRA, C. A. Melhoramento genético. In: MARTINS, E. G.; MEDRADO, M. J. S. Cultivo da grevílea nas regiões sul e sudeste do Brasil. Colombo, 2003. (Embrapa Florestas: Sistemas de Produção, 2). Disponível em http://sistemasdeproducao.cnptia.embrapa.br/ FontesHTML/Grevilea/CultivodaGrevileaSulSudeste/index.htm. Acesso em 26 jun 2009.

MARTINS, E. G. Seleção genética e características fisiológicas e nutricionais de procedências de Grevillea robusta (Cunn.) estabelecidas no Estado do Paraná. 2000. 126f. Tese (Doutorado em Ciências Florestais) - Setor de Ciências Agrárias, Universidade Federal do Paraná, Curitiba. 
MARTINS, E. G.; MEDRADO, M. J. S. Cultivo da grevílea nas regiões sul e sudeste do Brasil. Colombo, 2003. (Embrapa Florestas: Sistemas de Produção, 2). Disponível em http:// sistemasdeproducao.cnptia.embrapa.br/FontesHTML/Grevilea/ CultivodaGrevileaSulSudeste/index.htm. Acesso em 26 jun 2009.

MARTINS, E. G.; NEVES, E. J. M. Grevillea robusta (Cunn.): sementes melhoradas para usos múltiplos. Colombo, 2004. 4p. (Embrapa Florestas: Comunicado técnico, 126).

MARTINS, E. G.; NEVES, E. J. M. Melhoramento genético de grevílea para produção de madeira em pequenas propriedades. Colombo, 2005. (Embrapa Florestas: Boletim de Pesquisa e Desenvolvimento, 23). 1 CD-ROM.

MARTINS, E. G.; NEVES, E. J. M.; SHIMIZU, J. Y.; FERREIRA, C. A. Desempenho de procedências de grevílea em Anhembi, SP. Colombo, 2002. 5p. (Embrapa Florestas:

Comunicado Técnico, 69).
MARTINS, E. G.; NEVES, E. J. M.; STURION, J. A.; DULEBA, $\mathrm{N}$. Volume de madeira e ganho genético de progênies de grevílea (Grevíllea robusta Cunn.) de segunda geração na região de Londrina, Paraná. Boletim de Pesquisa Florestal, Colombo, n. 51, p. 45-55, jul./dez. 2005.

MARTINS, E. G.; SHIMIZU, J. Y. Produtividade de madeira das novas introduções de grevílea em Foz do Iguaçu. Colombo, 2003. 3p. (Embrapa Florestas: Comunicado Técnico, 95).

SHIMIZU, J. Y.; MARTINS, E. G.; FERREIRA, C. A. Avaliação inicial de procedências de grevílea no Noroeste do Paraná. Boletim de Pesquisa Florestal, Colombo, n. 37, p. 41-54, jul./ dez. 1998.

Recebido em 06 de julho de 2009 e aprovado em 08 de julho de 2010 